\title{
Study of Density Distribution in Entrained Plasma
}

\author{
**Khalid A.Yahya *Sabah N.Mazher *Zaidun A.Hafidh
}

Date of acceptance 2/4/2007

\begin{abstract}
:-
A theoretical investigation is carried out to study the effect of a pencil electron beam propagating inside the plasma region determining the hydrodynamic densities distribution with the aid of numerical analysis finite deference method (FDM). The plasma is generated and trapped by annular electron beams of fixed electron density $1 \times 10^{14} \mathrm{~m}^{-3}$.

The result of the study shows that the hydrodynamic density behaves as the increase in pencil electron beam. The hydrodynamic density ratio goes to more than double as the increase in pencil electron beam density to $1 \times 10^{18} \mathrm{~m}^{-3}$.
\end{abstract}

\section{I-Introduction :-}

The interaction of electron beam with plasma have received considerable attention due to its numerous application in acceleration of charged particles , plasma heating and amplification with generation of microwave devices $[1,2,3,4]$.

The purpose of this paper is to present the results of theoretical study of the parameters related to the effect of electron beam on the hydrodynamic density in plasma region.

\section{II-Proposed Geometry and basic equations:-}

The model consists of symmetric annular electron beam, which is used for generating the background plasma in the ionization chamber due to the impact of the electron beam with atom of gas in the chamber.A second fine electron beam, called the pencil beam, which independently generated and interacts with the trapped plasma. The two beams systems are shown in fig.(1) [5].

The distribution of plasma potential with pencil electron beam is determine by using Poisson's equation from eq.(1) [6]

$$
\frac{d E}{d \xi}=\frac{\left(n_{P b}-n_{1}\right)}{\varepsilon_{o}}(-e)
$$

where $\mathrm{nPb}$ is the density of pencil electron beam, $\mathrm{n} 1$ is the ion density generated behind electron beam, $\xi$ is the distance behind the electron beam , $\varepsilon 0$ is the permittivity of free space and $\mathrm{E}$ is the electric field .

The finite difference method is used to determine the potential distribution in eq.(1) with a computer program called Poss program [5].

The distribution of ion velocities in $\mathrm{x}$ and $\mathrm{y}$ direction can be determine by using Poss and Velos programs for different values of pencil electron beam densities [5].

The distribution of hydrodynamic density $\rho$ can be determined by using equation of continuity in plasma fluid theory $[7,8,9]$.

$$
\frac{\partial \rho}{\partial t}+\nabla \cdot\left(\rho_{o} v\right)=0
$$

where $\rho o$ is the primary density and $\rho$ is the hydrodynamic density after pencil electron beam interaction with plasma region .

\section{III-Hydrodynamic density:-}

To determine the hydrodynamic density distribution $\rho$, eq.(2) is used as follows :

$$
\begin{aligned}
& \vec{v}=\vec{i} v_{x}+\vec{j} v_{y} \\
& \vec{\nabla}=\vec{i} \frac{\partial}{\partial x}+\vec{j} \frac{\partial}{\partial y}
\end{aligned}
$$

where $v_{x}$ and $v_{y}$ are the velocities of ion

\footnotetext{
* Department of Physics, College of Science for women, University of Baghdad

**Department of Physics, College of Education, University of Anbar
} 
in $\mathrm{x}$ and $\mathrm{y}$ direction respectively. The solution of equation (2) is

$$
\Delta \rho=\rho_{o}\left(\frac{\partial v_{x}}{\partial x}+\frac{\partial v_{y}}{\partial y}\right) \Delta t
$$

where $\Delta \mathrm{t}$ is the increment in time .

A computer program called Hydro written in Fortran language, using eq.(5) and the results calculation from Poss and Velos programs to calculate the distribution of hydrodynamic it for different values of densities of pencil electron beam .

\section{IV- Results \& Conclusion :-}

Fig.(2) shows the results calculation from Poss and Velos program with pencil electron beam density $1 \times 1014 \mathrm{~m}$ 3 . The values of $v y=6.5 \times 105 \mathrm{~m} / \mathrm{s}$, shows the transverse ion oscillation in the entrained plasma region .

The results from Hydro program are shown in fig.( 3 ) to fig.( 5) . It is noticed from the figures that the interaction between the pencil beam and plasma leads to the increase of hydrodynamic density $\rho$ as the densities of electron pencil beam nP increases as shown in table(I).Fig.(6) shows the hydrodynamic density along the y axis at peak value for various values of pencil electron beam densities. From fig.(6) ,the maximum values of hydrodynamic density $\rho$ max and the minimum values of hydrodynamic density pmin shown in table (I) . The build up potential due to slow secondary electrons tangent to the inner annular beam boundary of the plasma model, is expressed by $\rho$ min .The value of space charge neutralization is expressed by $r \rho$ which corresponds to the value of $\left(\rho_{\max } / \rho_{\min }\right)$ and behaves indirectly as electron beam density of pencil beam .

The numerical calculation in the present model of electron beam plasma interaction, gives compaction $\operatorname{ratio}\left(\rho / \rho_{o}\right)$ of density distribution to more than double , and is a function of electron pencil beam density .

The hydrodynamic density distribution ,shown in fig.(6) as function of electron pencil beam density is the gain curve representation as charge neutralization of entrained plasma .The similar drop in density at both sides is due to equality of transverse charge oscillation in collision chamber .

\section{References :-}

1.Thoposon.M.C. and Rosenzweig . J.B. 2004" Plasma density transition trapping as a possible high- brightness electron beam source" Phys.Rev. Special topics Accelerators and beams 7:11301 .

2.Ordonez. C.A. 2003 “ Electron plasma ion trap/source "Appl.Phys. 94:3732 .

3.Barov.N , Conde.M.E , Gai.W and. Rosenzweig J.B 1998 “ Propagation of short electron pulse in plasma channel " Phys.Rev.Lett. 80:81 .

4.Suk.H , Hahn.S.J ,Kim.G and Ko.I.S. 2001“ Trapping of background plasma electron by plasma wake field "Proceeding of the second Asian Particle Accelerator conference Beijing, China .

5.Yahya.K.A. 2005 “ Study of electron beam - plasma interaction " Ph.D. Thesis ,Al-Mustansiriyah university ,Baghdad ,Iraq

6.Katsouleas.T. 1986“ Physical mechanisms in plasma wake field accelerator " Phys.Rev.A33:2056.

7.Chen F.F. 1974 " Introduction to plasma physics “ (Plenum press, New York and London ),

8.England.R.J ,Rosenzweig.J.B and Barov.N. 2002 " Plasma electron fluid motion and wave breaking new a density transition " Phys.Rev.E66:16501.

9.Chen.P ,Dawson.J.M ,Huff.R.W and Katsouleas.T. 1985 “ Acceleration of electron by interaction of bunched electron beam with plasma “ Phys.Rev.Lett.54:693.

Table (I) Maximum and minimum values for hydrodynamic density for different values of pencil electron beam np.

\begin{tabular}{|c|c|c|c|}
\hline $\mathrm{n}_{\mathrm{P}}\left(\mathrm{m}^{-3}\right)$ & $\rho_{\max }\left(\mathrm{gm} / \mathrm{cm}^{3}\right)$ & $\rho_{\min }\left(\mathrm{gm} / \mathrm{cm}^{3}\right)$ & $\mathrm{r}_{\rho}$ \\
\hline $1 \times 10^{14}$ & 31.6 & 5.82 & 5.42 \\
\hline $1 \times 10^{16}$ & 50.31 & 13.23 & 3.8 \\
\hline $1 \times 10^{18}$ & 69.72 & 45.1 & 1.5 \\
\hline
\end{tabular}



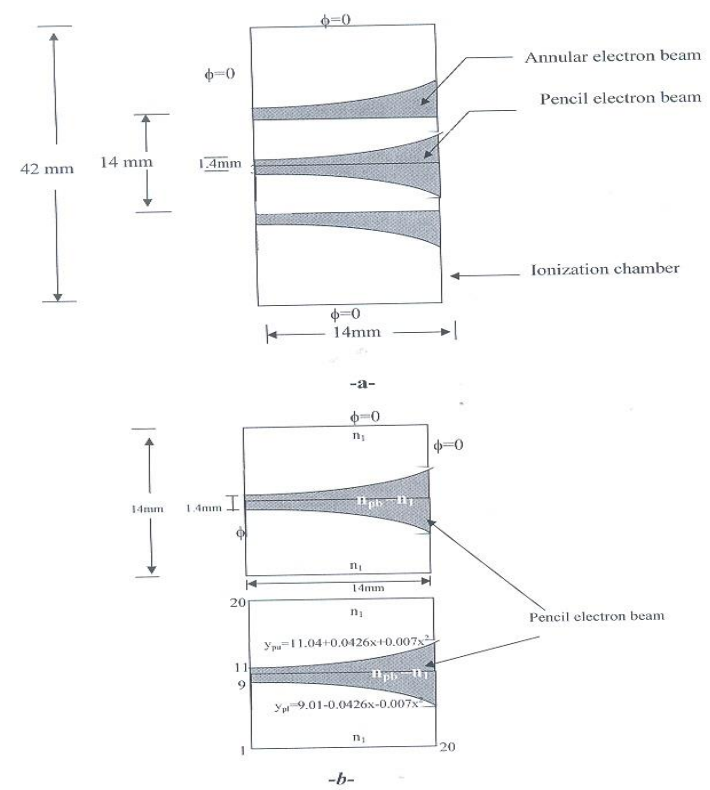

Fig.(1) a- Schematic diagram for the model and boundary condition b- Schematic diagram for pencil electron beam with plasma region

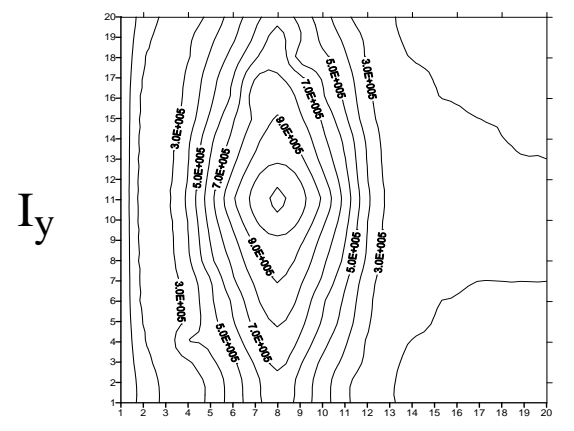

$\mathrm{I}_{\mathrm{X}}$

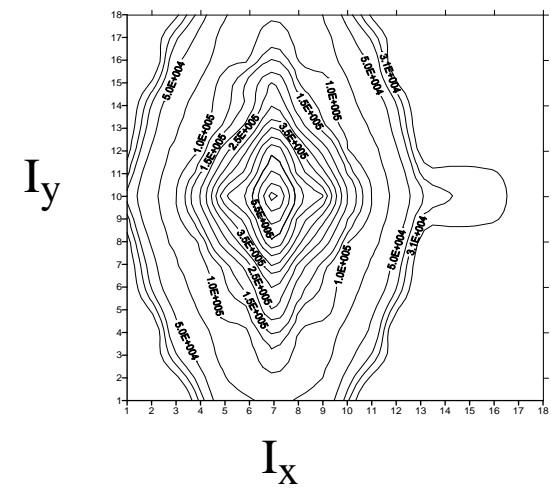

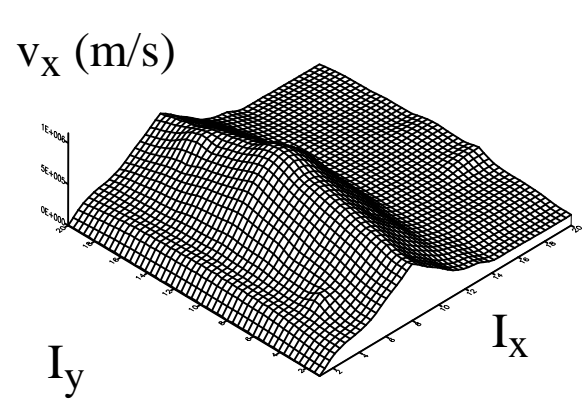

-a-

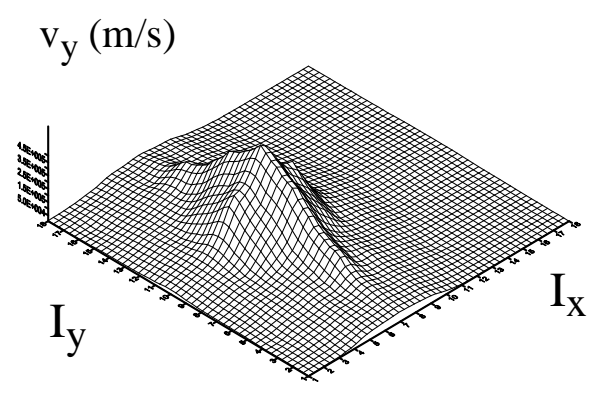

-b-

Fig.(2) Distribution of velocities with pencil electron beam density $1 \times 10^{14} \mathrm{~m}^{-3}$ from Poss and Velos program.

a- For velocities in $\mathrm{x}$ - direction

b- For velocities in $y$ - direction 

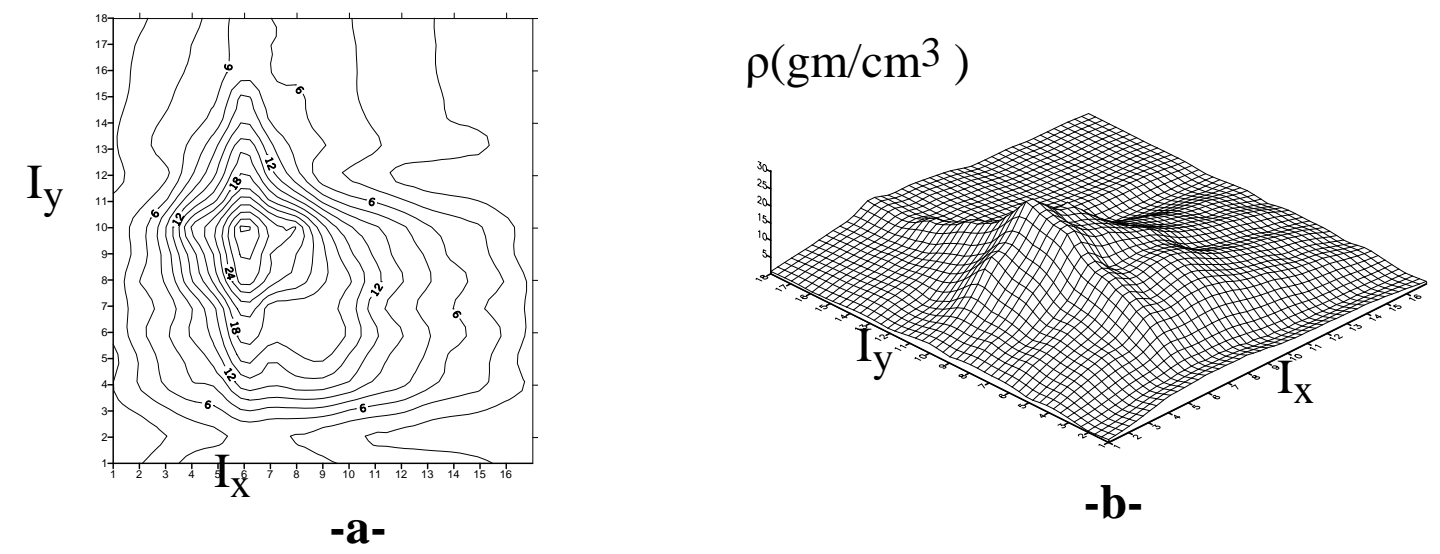

Fig.(3) Distribution of hydrodynamic density $(\rho)$ with pencil electron beam densities $\mathrm{n}_{\mathrm{pb}}=1 \times 10^{14} \mathrm{~m}^{-3}$ and $\rho_{\mathrm{o}}=19.07 \mathrm{gm} / \mathrm{cm}^{3}$

a-Contour hydrodynamic density

b- Surface hydrodynamic density
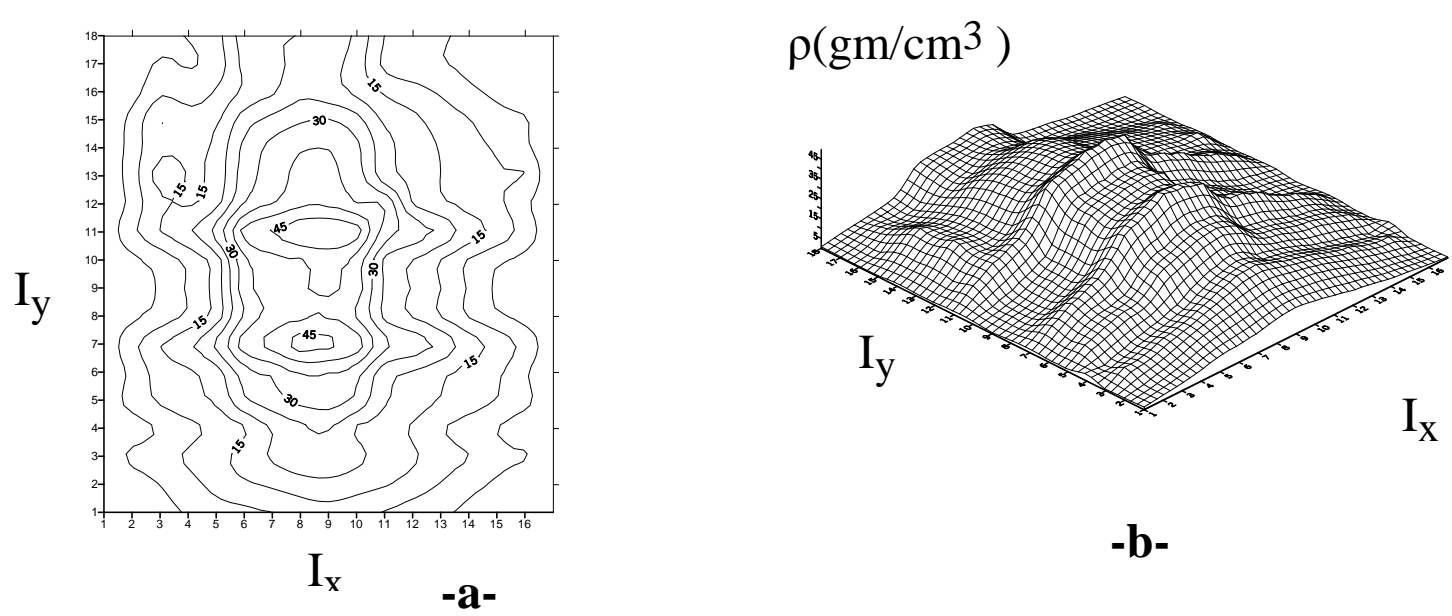

Fig.(4) Distribution of hydrodynamic density $(\rho)$ with pencil electron beam densities $\mathrm{n}_{\mathrm{pb}}=1 \times 10^{16} \mathrm{~m}^{-3}$ and $\rho_{\mathrm{o}}=19.07 \mathrm{gm} / \mathrm{cm}^{3}$

a-Contour hydrodynamic density

b- Surface hydrodynamic density
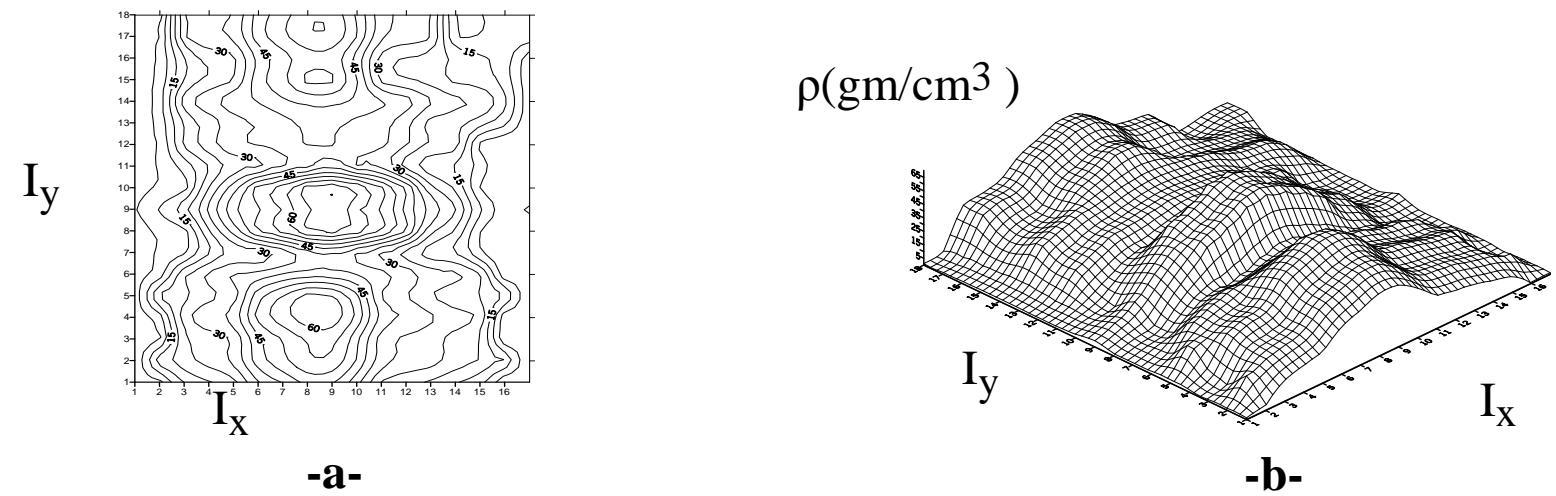

Fig.(5) Distribution of hydrodynamic density ( $\rho$ ) with pencil electron beam densities $n_{p b}$ $=1 \times 10^{18} \mathrm{~m}^{-3}$ and $\rho_{\mathrm{o}}=19.07 \mathrm{gm} / \mathrm{cm}^{3}$ a-Contour hydrodynamic density b- Surface hydrodynamic density 


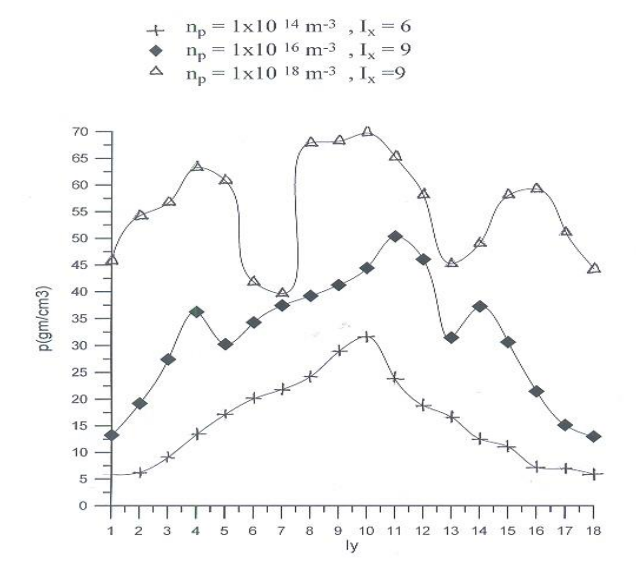

Fig. (6) The hydrodynamic density at peak values in $y$-direction for Fig. (6) The hydrodynamic density at peak values in
different values of pencil electron beam densities.

\section{دراسة توزيع الكثافة داخل البلازما}

* زيدون أحمد حافظ * - (

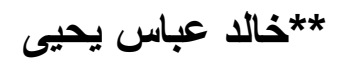

* قسم الفيزياء ، كلية العلوم للبنات ، جامعة بغداد الزباد

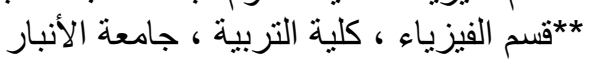

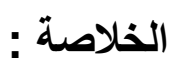

لقد اجريت دراسة نظرية لدراسة تأثير حزمة ألكترونية أصبعية (Pencil electron beam) تنفذ داخل

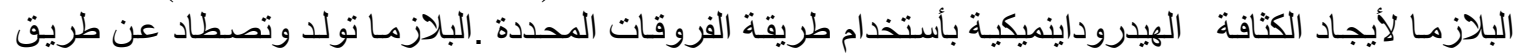

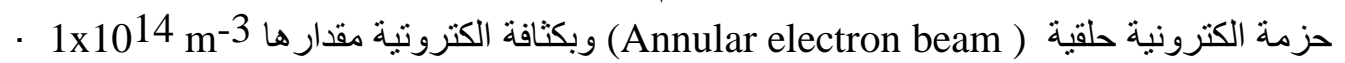

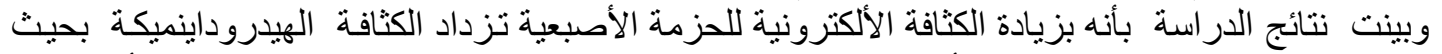

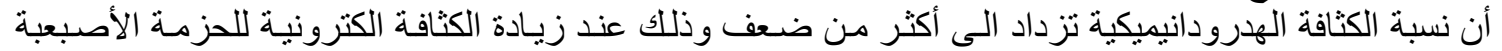
1x1018 m-3 داخل البلازما. 